\title{
Efficacy of Antidepressants for Depression in Alzheimer's Disease: Systematic Review and Meta-Analysis
}

\author{
Vasiliki Orgeta*, Naji Tabet, Ramin Nilforooshan and Robert Howard \\ University College London, Brighton and Sussex Medical School and Surrey and Borders Partnership NHS \\ Foundation Trust, London, UK
}

Handling Associate Editor: Jeannie-Marie Leoutsakos

Accepted 20 March 2017

\begin{abstract}
.
Background: Depression is common in people with Alzheimer's disease (AD) affecting overall outcomes and decreasing quality of life. Although depression in AD is primarily treated with antidepressants, there are few randomized controlled trials (RCTs) assessing efficacy and results have been conflicting.

Objectives: To systematically review evidence on efficacy of antidepressant treatments for depression in AD.

Methods: Systematic review and meta-analysis of double blind RCTs comparing antidepressants versus placebo for depression in AD. We searched MEDLINE, CINAHL, EMBASE, PsycINFO, the Cochrane Controlled Trials Register and on line national and international registers. Primary outcomes were treatment response and depressive symptoms. Secondary outcomes were cognition, acceptability, and tolerability. Risk of bias was also assessed.

Results: Seven studies met inclusion criteria. Three compared sertraline with placebo; one compared both sertraline and mirtazapine to placebo; imipramine, fluoxetine, and clomipramine were evaluated in one study each. In terms of response to treatment (6 studies, 297 patients treated with antidepressants and 223 with placebo), no statistically significant difference between antidepressants and placebo was found (odds ratio (OR) 1.95, 95\% CI 0.97-3.92). We found no significant drugplacebo difference for depressive symptoms ( 5 studies, 311 patients, SMD -0.13 ; $95 \%$ CI -0.49 to 0.24 ). Overall quality of the evidence was moderate because of methodological limitations in studies and the small number of trials.

Conclusion: Despite the importance of depression in people with AD, few RCTs are available on efficacy of antidepressants, limiting clear conclusions of their potential role. There is a need for further high quality RCTs.
\end{abstract}

Keywords: Antidepressants, Alzheimer's disease, depression, effectiveness, meta-analysis, randomized controlled trials

\section{INTRODUCTION}

Alzheimer's disease (AD) is a primary neurodegenerative dementia and is one of the leading causes of disability in older people [1,2]. While progressive

\footnotetext{
${ }^{*}$ Correspondence to: Dr. Vasiliki Orgeta, Alzheimer's Society Senior Fellow, Senior Research Associate, University College London, Division of Psychiatry, 6th Floor, Maple House, 149 Tottenham Court Road, London W1T 7NF, UK. Tel.: +44 0207679 9294; Fax: +44 0207679 9426; E-mail: v.orgeta@ucl.ac.uk.
}

cognitive impairment is the hallmark of the illness, neuropsychiatric symptoms affect almost all patients and are persistent $[3,4]$. Depression is one of the most common neuropsychiatric symptoms in $\mathrm{AD}$, associated with institutionalization [5] and mortality [6, 7]. Up to $50 \%$ of $\mathrm{AD}$ patients experience depression or clinically significant depressive symptoms during the course of the disease [8]. Major depressive disorder affects approximately $20 \%$ to $30 \%$ of people with $\mathrm{AD}[9,10]$, and personal or family history of 
depression [11], and younger age at onset of dementia are risk factors [12]. Depressive symptoms are more common than clinical depression [13, 14], and are highly persistent [10]. Depression and depressive symptoms increase the risk of behavioral disturbance and accelerate functional decline [15].

Antidepressants remain the mainstay of treatment for AD patients with depression. This is driven by a lack of alternative treatment options and a perception that antidepressants are effective in this population [16]. In line with a recent clinical review of the literature [17], there does not appear to be clear evidence from systematic reviews and meta-analyses to support this practice. Several randomized controlled trials (RCTs) testing antidepressants versus placebo have produced conflicting results [18-22]. In an antidepressants withdrawal study, patients with neuropsychiatric symptoms showed a worsening of depressive symptoms compared to those who continued treatment [23].

There is conflicting evidence on the effects of antidepressants on cognition, with some studies reporting a beneficial effect [24-26] and some harmful [27]. Psychological therapies have also been studied for depression in AD, with a systematic review reporting that current evidence is limited due to the small number of trials and varying approaches used [28].

Use of antidepressants in $\mathrm{AD}$ is associated with significant side-effects including hyponatremia [29], cardiotoxicity [30] and increased bleeding tendency $[27,31,32]$. Effectiveness of antidepressants in $\mathrm{AD}$ has been evaluated by narrative reviews [33], whereas quantitative reviews and meta-analyses have examined effectiveness in all types of dementia but have not included latest studies conducted [34, 35]. In this review, we investigated efficacy and acceptability by conducting a comprehensive, recent, worldwide review of the literature of antidepressants for depression in $\mathrm{AD}$.

\section{METHODS}

We searched major health databases such as MEDLINE, EMBASE, CINHAL, PsycINFO, and the Cochrane library for ongoing trials, as well as national and international trial registers, to March 2016. We searched for all depression AD RCTs with additional search terms (including each antidepressant as a separate term, see Supplementary Material for the full search strategy). We scanned the reference lists of all included studies and 82 reviews in the area of depression in $\mathrm{AD}$ and other dementias.

Inclusion criteria were: (1) RCTs comparing any single antidepressants with placebo, (2) people with a diagnosis of $\mathrm{AD},(3)$ patients with a diagnosis of depression as confirmed by either Diagnostic and Statistical Manual of Mental Disorders criteria [36] or either disease-specific criteria [14] or a validated rating scale for depression in older people. Validated scales included those used in both clinical and research settings in old age psychiatry [37], such as the Hamilton Depression Rating Scale [38], the Montgomery Asberg Depression Rating Scale [39], and the Cornell Scale for Depression in Dementia [40].

There were no restrictions in terms of participant characteristics, or class of antidepressants and studies in minor depression in AD were considered eligible. Studies that compared two treatment groups with placebo were included as long as there were separate results reported on the effects of each of the antidepressants. Primary outcomes were response to treatment and mean depression scores between the treatment and placebo groups. Secondary outcomes were cognition, number of drop-outs, and number of adverse events. We used a random-effects model to represent overall estimate effects, and where appropriate, used standardized mean differences as not all studies used the same outcome measures of depression. Heterogeneity was assessed with the chisquared test.

Two reviewers independently extracted data (VO, $\mathrm{RN}$ ), and any disagreements were resolved with a third author (NT). We used Revman 5.3.5. for data analysis, and the Risk of Bias Tool as recommended by the Cochrane Handbook to assess risk of bias in the included studies, which was assessed independently $(\mathrm{VO}, \mathrm{RN}$ ) (on domains of sequence generation, allocation concealment, blinding, incomplete outcome data, and selective reporting). Disagreement on quality of studies was low and was resolved by authors' consensus. We used the GRADE approach [41] to summarize overall quality of evidence. We identified a total of 3,808 references through database searching and 13 additional references via other sources (reference lists of identified studies and reviews of the literature). After removal of duplicates and clearly irrelevant articles we retrieved 148 full text records. Irrelevant articles were those that were not directly relevant to the study of effectiveness of antidepressants in depression in older people with cognitive impairment and/or dementia. Of the 148 full text 


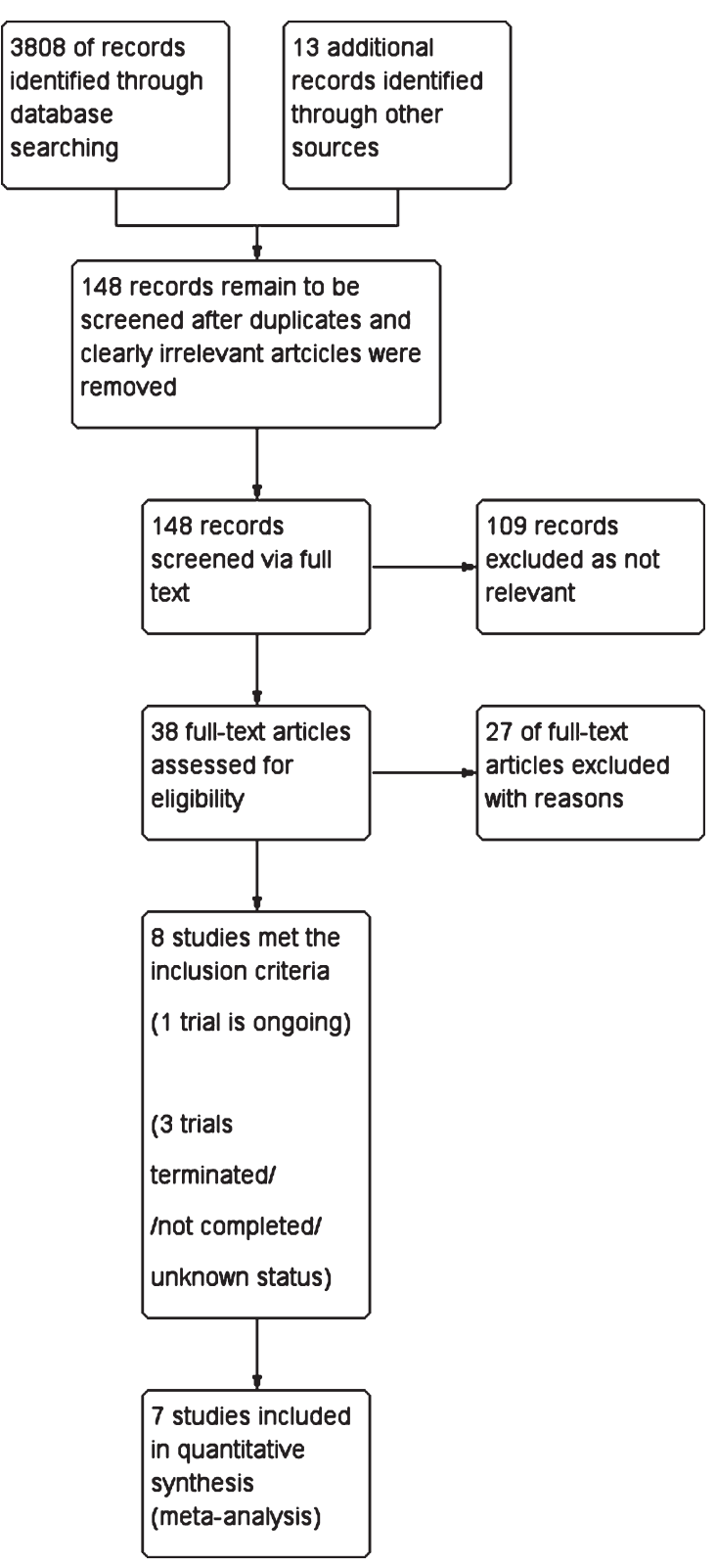

Fig. 1. Flow diagram of the review.

records, we excluded 109 as not relevant, leaving 38 full text references to be fully assessed for eligibility. A further 27 were excluded as not meeting criteria of this review (see Supplementary Table 1 for details). We identified one ongoing study [42] (DIADs-3) investigating the effectiveness of venlafaxine, and three trials which were terminated [43], or completed without published outputs or are of unknown status $[44,45]$. A total of 7 studies met the inclusion criteria. Figure 1 shows details of the search process.

\section{RESULTS}

\section{Antidepressants versus placebo}

Three studies compared sertraline with placebo [19, 21, 46], one RCT compared both sertraline and mirtazapine to placebo [47]; imipramine [20], fluoxetine [22], and clomipramine [18] were examined in one study each.

\section{Primary outcome}

Response to treatment (dichotomous outcome)

Efficacy at 6-13 weeks and 24-39 weeks. Six studies (involving 520 patients) contributed data on shortterm response [18, 19, 21, 22, 46, 47]. There was no statistically significant difference on odds of response between antidepressants and placebo (OR 1.95, 95\% confidence interval (CI) 0.97 to $3.92, p=0.06$ ) (see Fig. 2). There was significant heterogeneity between studies $\left(I^{2}=61 \%\right)$. Only two studies (involving 359 patients) contributed data on long-term response [46, 47]. The odds of response did not differ between antidepressants and placebo (OR 1.08, 95\% CI 0.69 to $1.69, p=0.74, I^{2}=8 \%$ ).

\section{Mean depression scores (continuous outcome)}

Efficacy at 6-13 weeks and 39 weeks. There were no statistically significant difference between antidepressants and placebo, with a standardized mean difference of -0.13 (95\% CI -0.49 to 0.24 , five studies, 311 participants) (see Fig. 3), with moderate heterogeneity between studies $\left(I^{2}=50 \%\right)$ [19-22, 47]. Only one study [47] contributed data on longterm response for mean depressive symptoms; mean difference of -0.00 ( $95 \%$ CI -1.77 to $1.77,1$ study, 150 participants).

\section{Secondary outcomes}

\section{Cognition (MMSE scores) (continuous outcome)}

Efficacy 6-13 weeks. Five studies [18-20, 22, 47] provided data for this outcome, showing no statistically significant difference between antidepressants and placebo, with a mean difference of 0.14 (95\% CI -1.65 to $1.93,251$ participants, $I^{2}=0 \%$, Fig. 4 ).

\section{Acceptability: Number of drop-outs (dichotomous outcome)}

Efficacy 6-13 weeks and 24-39 weeks. At 6-13 weeks, similar numbers of patients dropped out of the intervention and control groups (OR 1.40, 95\% CI 0.88 to $2.23, p=0.15$; seven studies, 523 partici- 


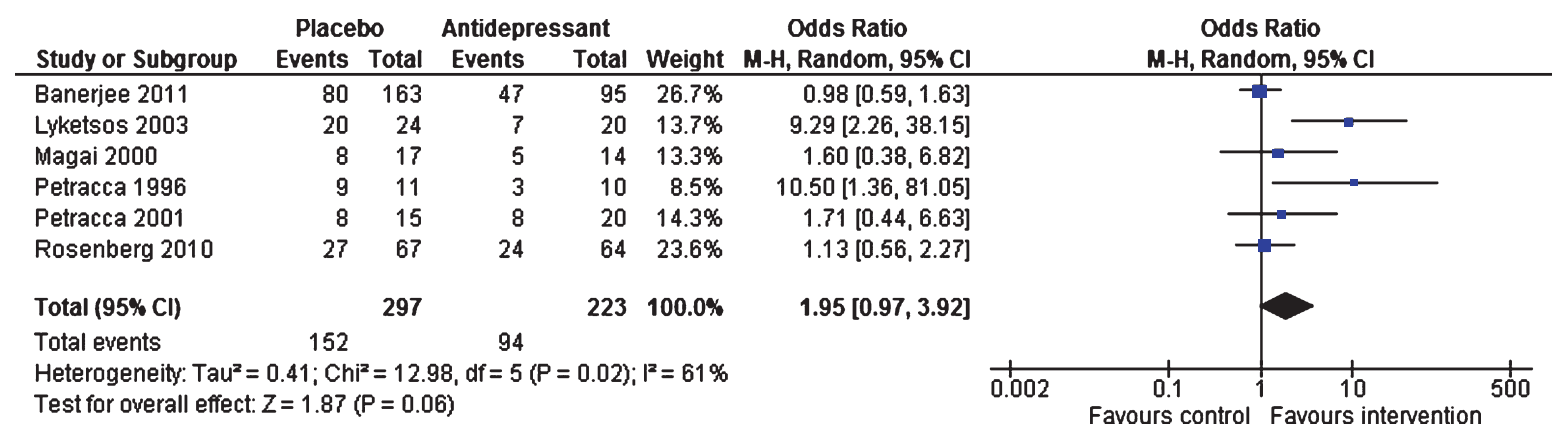

Fig. 2. Forest plot of comparison of antidepressants versus placebo: Response to treatment (6-13 weeks).

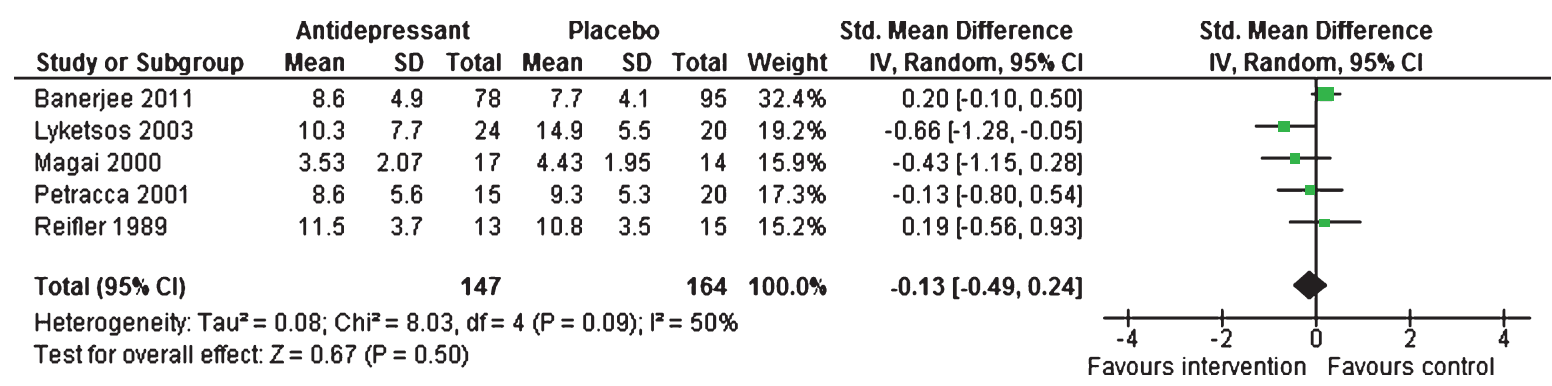

Fig. 3. Forest plot of comparison of antidepressants versus placebo: Mean depression scores (6-13 weeks).

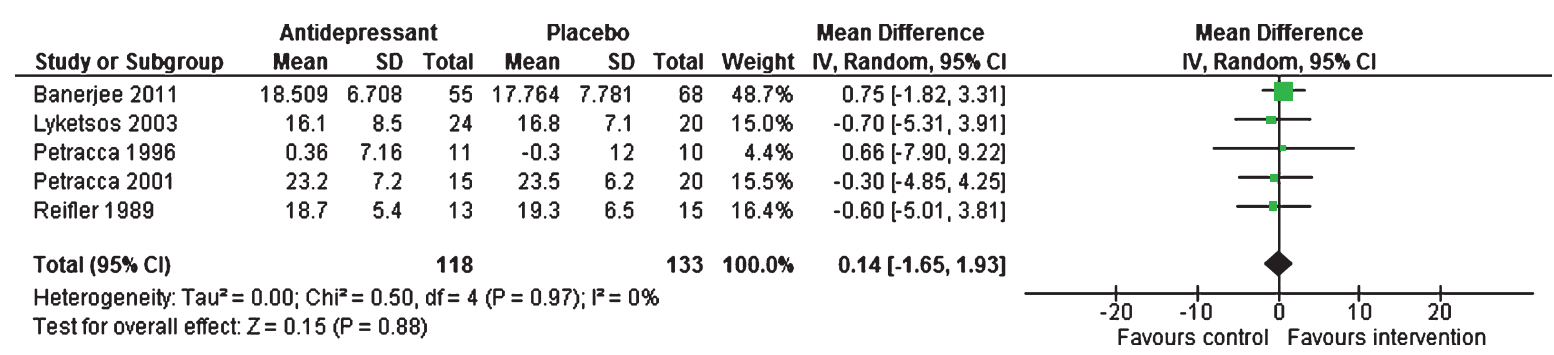

Fig. 4. Forest plot of comparison of antidepressants versus placebo: Cognition MMSE scores (6-13 weeks).

pants, $I^{2}=0 \%$, Fig. 5), with all studies contributing to the analyses [18-22, 46, 47]. Data from two studies $[46,47]$ showed that there were no differences between the two groups on number of drop-outs for long-term response (OR 1.31, 95\% CI 0.81 to 2.13, $p=0.27 ; 347$ participants, $I^{2}=15 \%$ ).

\section{Tolerability: Number of adverse events \\ (dichotomous outcome)}

Efficacy 6-13 weeks and 39 weeks. Although more adverse events were reported by patients in the intervention group, there were no significant differences overall between the two groups (OR 1.91, 95\% CI 0.92 to $3.96, p=0.08$; seven studies; [18-22, 46, 47] 632 patients, $I^{2}=0 \%$, Fig. 6). One trial [47] contributed data on adverse events long-term (OR 1.30,
95\% CI 0.67 to $2.54, p=0.44 ; 326$ participants), with no differences between the two groups.

\section{Risk of bias and overall quality of evidence}

Figure 7 shows authors' judgements about each risk of bias item presented as percentages across all included studies. As can be seen from the graph, bias was detected predominantly in the domains of sequence generation and blinding of outcome, limitations applicable to earlier studies. Using the GRADE approach, the overall quality of evidence was judged as moderate indicative of a possibility that a new trial added to the meta-analysis could change the estimate of the effect (see Supplementary Figure 1). 


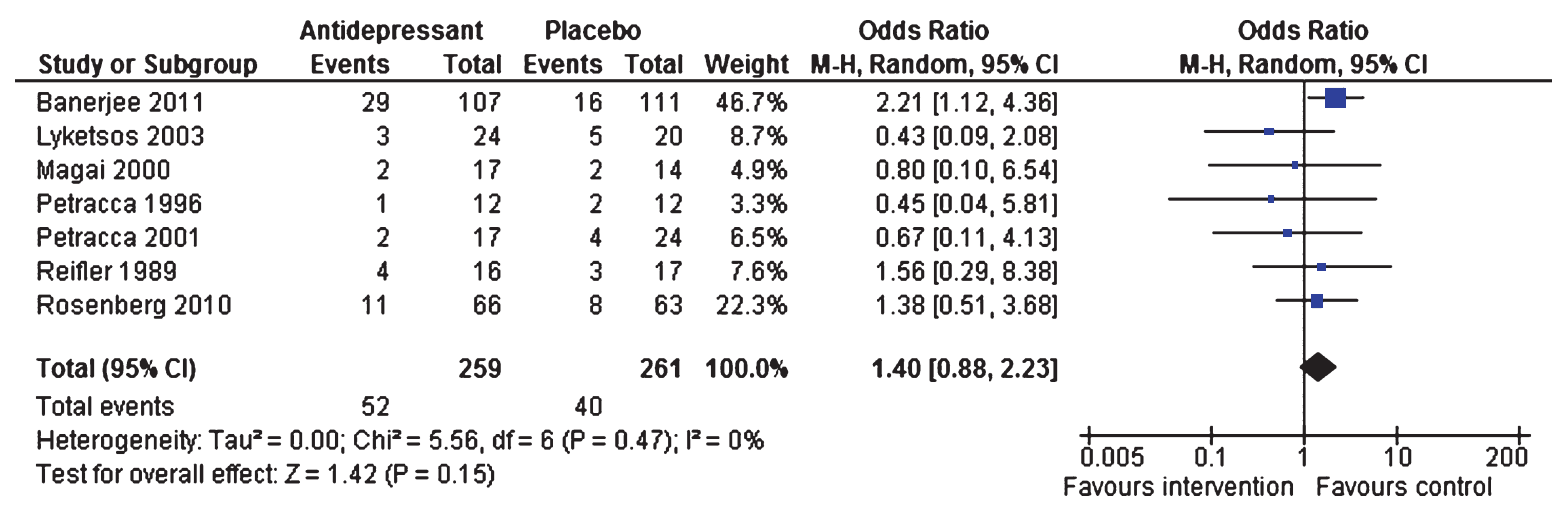

Fig. 5. Forest plot of comparison of antidepressants versus placebo: Acceptability Number of drop-outs (6-13 weeks).

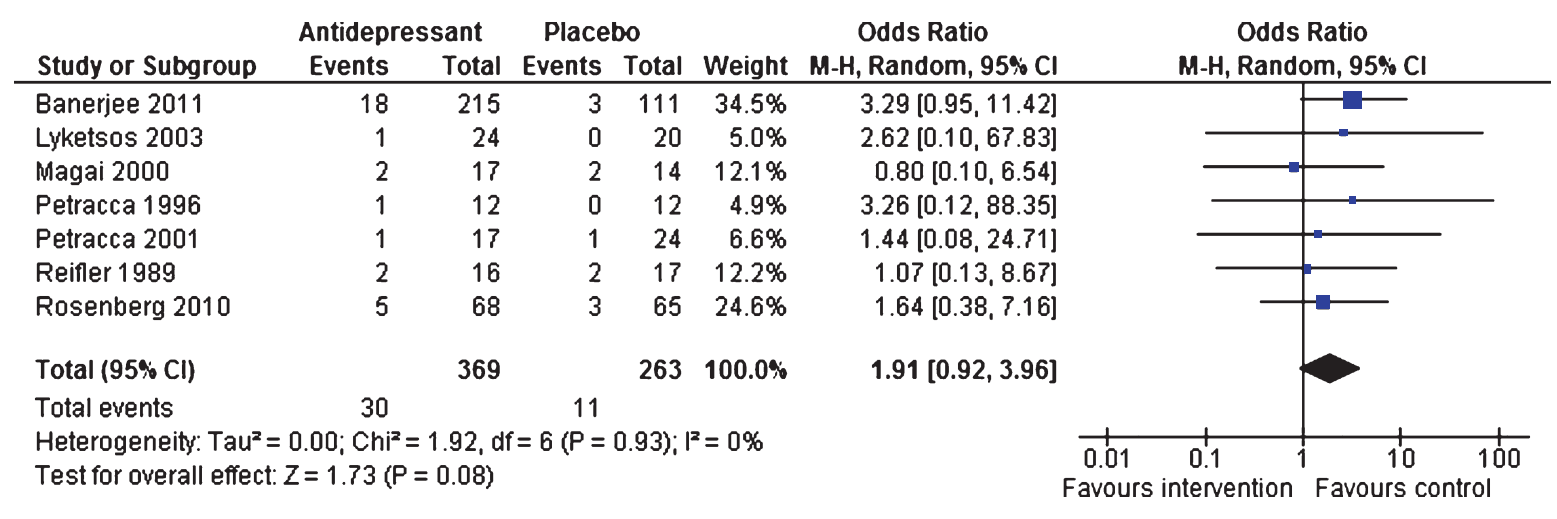

Fig. 6. Forest plot of comparison of antidepressants versus placebo: Tolerability Number of adverse events (6-13 weeks).

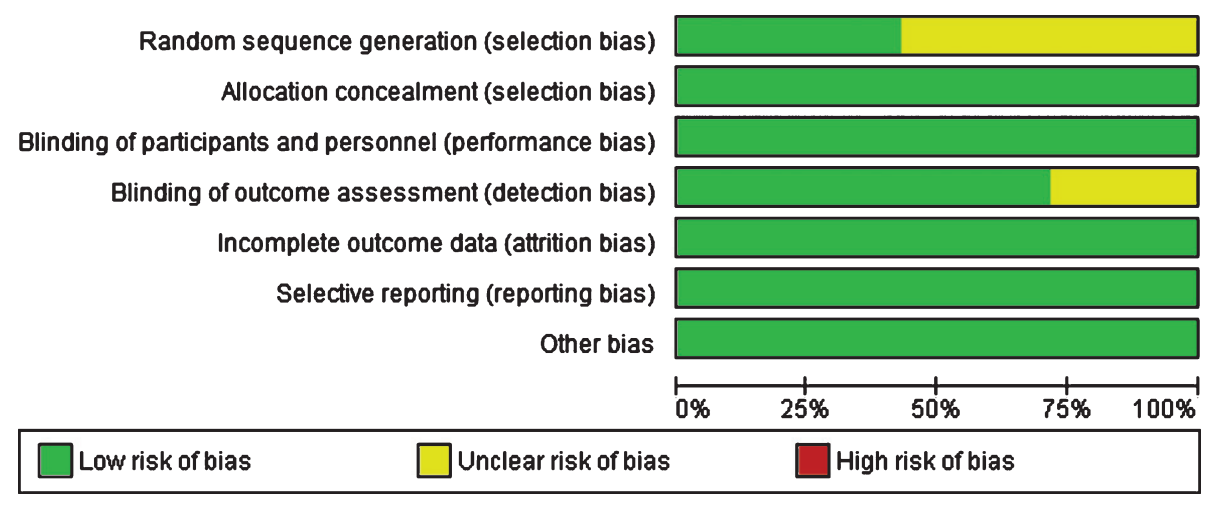

Fig. 7. Risk of bias graph: review authors' judgements about each risk of bias item presented as percentages across all included studies.

\section{DISCUSSION}

We found that the overall evidence of effectiveness for antidepressants in people with AD is small, with only a few clinical trials conducted to date. Our pooled meta-analysis (6 RCTs, 297 patients treated with antidepressants and 223 with placebo) failed to show significant differences between antidepressants and placebo for response to treatment. Although the overall difference between antidepressants and placebo failed to reach accepted levels of statistical significance, the analysis trended toward treatment response $(p=0.06)$, with the smaller trials contributing a positive effect of antidepressants. Although our overall analyses were negative, we cannot fully rule out a possible clinical advantage of antidepressants 
because of the paucity of RCTs. As most studies to date except for the Banerjee et al. [47] trial have been small, we conclude that further research is required to definitively confirm or refute effectiveness.

Data from five studies from 311 participants (147 treated with antidepressants and 164 with placebo) showed that antidepressants were not superior to placebo in terms of depressive symptoms. For continuous scores, the majority of studies used the Hamilton Depression Rating Scale for Depression [38], which has not been validated for use in patients with $\mathrm{AD}$, while the remaining studies used the Cornell Scale for Depression in Dementia [40]. No research evidence or consensus exists as to what constitutes a clinically meaningful difference in depressive symptoms between drug and placebo treatment in AD. The National Institute for Health and Clinical Excellence requires a difference of at least three points as a criterion for clinically significant change in depression in the general population [48].

When we examined other outcomes, we found no significant differences in drop-out between antidepressants and placebo, and no differences in effect on cognition. For tolerability, although more adverse events were reported in the antidepressant group, there were no significant differences.

Risk of bias analyses showed that although all included studies were double blind RCTs, there was evidence of unclear risk in some domains, mostly within the earlier studies. Based on the GRADE system, we were able to classify the overall quality of evidence as 'moderate' for both treatment response and depressive symptoms, because of methodological limitations and the limited number of trials.

This review followed guidelines set out by the Cochrane Collaboration [49]. We used a comprehensive and sensitive strategy to identify all RCTs reported in the literature, and selection of studies, data extraction, and assessments of risk of bias were independently conducted by two authors. However, there are limitations to our review. Identified RCTs were heterogeneous with regards to participants selected and the type of treatments involved, as the class of antidepressant differed and in two of the trials not all participants had major depression. Duration of exposure to antidepressants also differed and the majority of RCTs contributing data to the meta-analysis had fewer than 50 participants. It was not possible to test for publication bias which may have influenced the results.

\section{Implications for practice and research}

The small number of studies and the variations in terms of type of antidepressant tested make it difficult to draw conclusions about the effectiveness of pharmacological treatments for depression in people with AD. There is a need for further welldesigned multicenter RCTs which adhere to high standards of methodology and reporting and include diagnostically homogenous populations and large samples. The lack of evidence base makes it difficult to use this research to inform evidence-based policy about whether antidepressants are effective in treating depression in people with AD.

Interaction effects may have contributed to the results of this review such as type of antidepressant, dose, and severity of depressive symptoms and should be investigated in future research. Results of our review suggest that the pathophysiology of depression in $\mathrm{AD}$ may be different to that of primary depression, as indicated by lack of evidence of pathological changes in monoaminergic nuclei in people with $\mathrm{AD}[50,51]$, and may therefore explain lack of efficacy of conventional antidepressant treatments. An alternative hypothesis to underlying deficits in monoamine neurotransmitters includes deficits in glutamatergic transmission, which has led to a call for further research in identifying biomarkers and treatments for depression in $\mathrm{AD}$ that extent beyond the monoaminergic hypothesis [52].

Despite the limited and contradictory evidence regarding efficacy of antidepressants in AD, they are still commonly prescribed. David et al. reported a significant increase in prescribing rates from $26 \%$ in 2010 to $31 \%$ in 2014 [53], and similar rates have been seen in other studies [54, 55]. It is possible that attempts to reduce use of antipsychotics in people with dementia have contributed to this. Given evidence that apathy is a co-morbid factor of depression in $\mathrm{AD}$ [56], associated with different outcomes, it will be important for future studies to report whether people with clinically significant symptoms of apathy are excluded from antidepressants trials research.

To conclude, this is an up-to-date, methodologically rigorous meta-analysis on the efficacy of antidepressants for depression in patients with $\mathrm{AD}$ including all available trials. We found no clear evidence to support the efficacy of antidepressants for treating depression in AD. These findings do not mean that people with severe depression and $\mathrm{AD}$ should not be treated with antidepressants. Given this review is limited by a paucity of trials, small 
studies overall and variation in patients recruited, further RCTs are needed to confirm the effects of antidepressants in AD.

\section{ACKNOWLEDGMENTS}

Vasiliki Orgeta, Division of Psychiatry, University College London, Naji Tabet, Brighton and Sussex Medical School, Ramin Nilforooshan, Surrey and Borders Partnership NHS Foundation Trust, Robert Howard, Division of Psychiatry, University College London. We would like to thank the Alzheimer's Society who funded Dr. Vasiliki Orgeta to undertake this research and all of the authors that provided data and further information for this review. RH is supported by the UCLH NIHR Biomedical Research Centre.

Authors' disclosures available online (http://j-alz. com/manuscript-disclosures/16-1247r1).

\section{SUPPLEMENTARY MATERIAL}

The supplementary material is available in the electronic version of this article: http://dx.doi.org/ 10.3233/JAD-161247.

\section{REFERENCES}

[1] Burns A, Iliffe S (2009) Dementia. BMJ 338, b75.

[2] Knapp M, Comas-Herrera A, Wittenberg R, Hu B, King D, Rehill A, Adelaja B (2014) Scenarios of dementia care: What are the impacts on cost and quality of life? PSSRU Discussion Paper, 2878, Personal Social Services Research Unit, London, UK.

[3] Fernandez M, Gobartt AL, Balana M, COOPERA Study Group (2010) Behavioural symptoms in patients with Alzheimer's disease and their association with cognitive impairment. BMC Neurol 10, 87-2377-10-87.

[4] Kales HC, Gitlin LN, Lyketsos CG (2015) Assessment and management of behavioral and psychological symptoms of dementia. BMJ 350, h369.

[5] Gaugler JE, Yu F, Krichbaum K, Wyman JF (2009) Predictors of nursing home admission for persons with dementia. Med Care 47, 191-198.

[6] Burns A, Lewis G, Jacoby R, Levy R (1991) Factors affecting survival in Alzheimer's disease. Psychol Med 21, 363-370.

[7] Suh GH, Kil Yeon B, Shah A, Lee JY (2005) Mortality in Alzheimer's disease: A comparative prospective Korean study in the community and nursing homes. Int $J$ Geriatr Psychiatry 20, 26-34.

[8] Starkstein SE, Jorge R, Mizrahi R, Robinson RG (2005) The construct of minor and major depression in Alzheimer's disease. Am J Psychiatry 162, 2086-2093.

[9] Enache D, Winblad B, Aarsland D (2011) Depression in dementia: Epidemiology, mechanisms, and treatment. Curr Opin Psychiatry 24, 461-472.
[10] Ballard C, Bannister C, Solis M, Oyebode F, Wilcock G (1996) The prevalence, associations and symptoms of depression amongst dementia sufferers. J Affect Disord 36, 135-144.

[11] Strauss ME, Ogrocki PK (1996) Confirmation of an association between family history of affective disorder and the depressive syndrome in Alzheimer's disease. Am J Psychiatry 153, 1340-1342.

[12] Butt ZA, Strauss ME (2001) Relationship of family and personal history to the occurrence of depression in persons with Alzheimer's disease. Am J Geriatr Psychiatry 9, 249254.

[13] Migliorelli R, Teson A, Sabe L, Petracchi M, Leiguarda R, Starkstein SE (1995) Prevalence and correlates of dysthymia and major depression among patients with Alzheimer's disease. Am J Psychiatry 152, 37-44.

[14] Olin JT, Schneider LS, Katz IR, Meyers BS, Alexopoulos GS, Breitner JC, Bruce ML, Caine ED, Cummings JL, Devanand DP, Krishnan KR, Lyketsos CG, Lyness JM, Rabins PV, Reynolds CF, 3rd, Rovner BW, Steffens DC, Tariot PN, Lebowitz BD (2002) Provisional diagnostic criteria for depression of Alzheimer disease. Am J Geriatr Psychiatry 10, 125-128.

[15] Lyketsos CG, Steele C, Baker L, Galik E, Kopunek S, Steinberg M, Warren A (1997) Major and minor depression in Alzheimer's disease: Prevalence and impact. J Neuropsychiatry Clin Neurosci 9, 556-561.

[16] Kessing LV, Harhoff M, Andersen PK (2007) Treatment with antidepressants in patients with dementia-a nationwide register-based study. Int Psychogeriatr 19, 902-913.

[17] Siarkos KT, Katirtzoglou EA, Politis AM (2015) A review of pharmacological treatments for depression in Alzheimer's disease. J Alzheimers Dis 48, 15-34.

[18] Petracca G, Teson A, Chemerinski E, Leiguarda R, Starkstein SE (1996) A double-blind placebo-controlled study of clomipramine in depressed patients with Alzheimer's disease. J Neuropsychiatry Clin Neurosci 8, 270-275.

[19] Lyketsos CG, DelCampo L, Steinberg M, Miles Q, Steele CD, Munro C, Baker AS, Sheppard JM, Frangakis C, Brandt J, Rabins PV (2003) Treating depression in Alzheimer disease: Efficacy and safety of sertraline therapy, and the benefits of depression reduction: The DIADS. Arch Gen Psychiatry 60, 737-746.

[20] Reifler BV, Teri L, Raskind M, Veith R, Barnes R, White E, McLean P (1989) Double-blind trial of imipramine in Alzheimer's disease patients with and without depression. Am J Psychiatry 146, 45-49.

[21] Magai C, Kennedy G, Cohen CI, Gomberg D (2000) A controlled clinical trial of sertraline in the treatment of depression in nursing home patients with late-stage Alzheimer's disease. Am J Geriatr Psychiatry 8, 66-74.

[22] Petracca GM, Chemerinski E, Starkstein SE (2001) A double-blind, placebo-controlled study of fluoxetine in depressed patients with Alzheimer's disease. Int Psychogeriatr 13, 233-240.

[23] Bergh S, Selbaek G, Engedal K (2012) Discontinuation of antidepressants in people with dementia and neuropsychiatric symptoms (DESEP study): Double blind, randomised, parallel group, placebo controlled trial. BMJ 344, e1566.

[24] Mossello E, Boncinelli M, Caleri V, Cavallini MC, Palermo E, Di Bari M, Tilli S, Sarcone E, Simoni D, Biagini CA, Masotti G, Marchionni N (2008) Is antidepressant treatment associated with reduced cognitive decline in Alzheimer's disease? Dement Geriatr Cogn Disord 25, 372-379. 
[25] Roth M, Mountjoy CQ, Amrein R (1996) Moclobemide in elderly patients with cognitive decline and depression: An international double-blind, placebo-controlled trial. Br J Psychiatry 168, 149-157.

[26] Nyth AL, Gottfries CG, Lyby K, Smedegaard-Andersen L, Gylding-Sabroe J, Kristensen M, Refsum HE, Ofsti E, Eriksson S, Syversen S (1992) A controlled multicenter clinical study of citalopram and placebo in elderly depressed patients with and without concomitant dementia. Acta Psychiatr Scand 86, 138-145.

[27] Porsteinsson AP, Drye LT, Pollock BG, Devanand DP, Frangakis C, Ismail Z, Marano C, Meinert CL, Mintzer JE, Munro CA, Pelton G, Rabins PV, Rosenberg PB, Schneider LS, Shade DM, Weintraub D, Yesavage J, Lyketsos CG, CitAD Research Group (2014) Effect of citalopram on agitation in Alzheimer disease: The CitAD randomized clinical trial. JAMA 311, 682-691.

[28] Orgeta V, Qazi A, Spector A, Orrell M (2015) Psychological treatments for depression and anxiety in dementia and mild cognitive impairment: Systematic review and metaanalysis. Br J Psychiatry 207, 293-298.

[29] De Picker L, Van Den Eede F, Dumont G, Moorkens G, Sabbe BG (2014) Antidepressants and the risk of hyponatremia: A class-by-class review of literature. Psychosomatics 55, 536-547.

[30] Sultana J, Spina E, Trifiro G (2015) Antidepressant use in the elderly: The role of pharmacodynamics and pharmacokinetics in drug safety. Expert Opin Drug Metab Toxicol 11, 883-892.

[31] Gahr M, Zeiss R, Lang D, Connemann BJ, Hiemke C, Muche R, Freudenmann RW, Schonfeldt-Lecuona C (2015) Association between haemorrhages and treatment with selective and non-selective serotonergic antidepressants: Possible implications of quantitative signal detection. Psychiatry Res 229, 257-263.

[32] Jasiak NM, Bostwick JR (2014) Risk of QT/QTc prolongation among newer non-SSRI antidepressants. Ann Pharmacother 48, 1620-1628.

[33] Farina N, Morrell L, Banerjee S (2017) What is the therapeutic value of antidepressants in dementia? A narrative review. Int J Geriatr Psychiatry 32, 32-49.

[34] Bains J, Birks J, Dening T (2002) Antidepressants for treating depression in dementia. Cochrane Database Syst Rev (4), CD003944.

[35] Thompson S, Herrmann N, Rapoport MJ, Lanctot KL (2007) Efficacy and safety of antidepressants for treatment of depression in Alzheimer's disease: A metaanalysis. Can J Psychiatry 52, 248-255.

[36] American Psychiatric Association (1994) Diagnostic and Statistical Manual of Mental Disorders (DSM-IV). American Psychiatric Association, Washington, DC.

[37] Burns A, Lawlor B, Craig S (2002) Rating scales in old age psychiatry. Br J Psychiatry 180, 161-167.

[38] Hamilton M (1960) A rating scale for depression. J Neurol Neurosurg Psychiatry 23, 56-62.

[39] Montgomery SA, Asberg M (1979) A new depression scale designed to be sensitive to change. Br J Psychiatry 134, 382-389.

[40] Alexopoulos GS, Abrams RC, Young RC, Shamoian CA (1988) Cornell scale for depression in dementia. Biol Psychiatry 23, 271-284.

[41] Atkins D, Best D, Briss PA, Eccles M, Falck-Ytter Y, Flottorp S, Guyatt GH, Harbour RT, Haugh MC, Henry D, Hill S, Jaeschke R, Leng G, Liberati A, Magrini N, Mason J, Middleton P, Mrukowicz J, O'Connell D, Oxman AD, Phillips B,
Schünemann HJ, Edejer T, Varonen H, Vist GE, Williams JW Jr, Zaza S; GRADE Working Group (2004) Grading quality of evidence and strength of reccomendations. BMJ 328, 1490.

[42] Rosenberg BP (2012) Venlafaxine for Depression in Alzheimer's DIsease (DIADs-3); https://clinicaltrials.gov/ ct2/show/NCT01609348.

[43] Rabheru K (2010) Escitalopram and Depression in Elderly Alzheimer's Patients; https://clinicaltrials.gov/ct2/ show/NCT00488670.

[44] Han S (2007) Escitalopram for the Treatment of Depression in Alzheimer's Disease; https://clinicaltrials.gov/ct2/ show/NCT01841125.

[45] Sverdlik A (2005) Study of Escitalopram Versus Placebo in the Treatment of Depressive Syndrome in Alzheimer's Disease, Vascular Dementia, and Mixed Vascular and Alzheimer's Dementia; https://clinicaltrials.gov/ ct2/show/NCT00229333.

[46] Rosenberg PB, Drye LT, Martin BK, Frangakis C, Mintzer JE, Weintraub D, Porsteinsson AP, Schneider LS, Rabins PV, Munro CA, Meinert CL, Lyketsos CG, DIADS-2 Research Group (2010) Sertraline for the treatment of depression in Alzheimer disease. Am J Geriatr Psychiatry 18, 136-145.

[47] Banerjee S, Hellier J, Dewey M, Romeo R, Ballard C, Baldwin R, Bentham P, Fox C, Holmes C, Katona C, Knapp M, Lawton C, Lindesay J, Livingston G, McCrae N, MonizCook E, Murray J, Nurock S, Orrell M, O’Brien J, Poppe M, Thomas A, Walwyn R, Wilson K, Burns A (2011) Sertraline or mirtazapine for depression in dementia (HTA-SADD): A randomised, multicentre, double-blind, placebo-controlled trial. Lancet 378, 403-411.

[48] National Collaborating Centre for Mental Health (2004) Depression: Management of Depression in Primary and Secondary Care (Clinical Guideline 23).

[49] Higgins J, Green S (2011) Cochrane Handbook for Systematic Reviews of Interventions Version 5.1.0, The Cochrane Collaboration.

[50] Hendricksen M, Thomas AJ, Ferrier IN, Ince P, O'Brien JT (2004) Neuropathological study of the dorsal raphe nuclei in late-life depression and Alzheimer's disease with and without depression. Am J Psychiatry 161, 1096-1102.

[51] Thomas AJ, Hendriksen M, Piggott M, Ferrier IN, Perry E, Ince P, O'Brien JT (2006) A study of the serotonin transporter in the prefrontal cortex in late-life depression and Alzheimer's disease with and without depression. Neuropathol Appl Neurobiol 32, 296-303.

[52] Khundakar AA, Thomas AJ (2015) Neuropathology of depression in Alzheimer's disease: Current knowledge and the potential for new treatments. J Alzheimers Dis 44, 27-41.

[53] David R, Manera V, Fabre R, Pradier C, Robert P, Tifratene $\mathrm{K}$ (2016) Evolution of the antidepressant prescribing in Alzheimer's disease and related disorders between 2010 and 2014: Results from the French National Database on Alzheimer's Disease (BNA). J Alzheimers Dis 53, 13651373.

[54] Laitinen ML, Lonnroos E, Bell JS, Lavikainen P, Sulkava R, Hartikainen S (2015) Use of antidepressants among community-dwelling persons with Alzheimer's disease: A nationwide register-based study. Int Psychogeriatr 27, 669672.

[55] Puranen A, Taipale H, Koponen M, Tanskanen A, Tolppanen AM, Tiihonen J, Hartikainen S (2017) Incidence of antidepressant use in community-dwelling persons with and 
without Alzheimer's disease: 13-year follow-up. Int J Geriatr Psychiatry 32, 94-101.

[56] Tagariello P, Girardi P, Amore M (2009) Depression and apathy in dementia: Same syndrome or different constructs? A critical review. Arch Gerontol Geriatr 49, 246-249. 